\title{
Investigation of the effect of tufts contribution on the in-plane mechanical properties of flax fibre reinforced green biocomposite
}

\author{
M. Rashid ${ }^{1 *}$ (D, J. L. Hanus ${ }^{2}$, K. Chetehouna ${ }^{1}$, K. Khellil ${ }^{3}$, Z. Aboura ${ }^{3}$ and N. Gascoin ${ }^{1}$
}

\begin{abstract}
Traditional laminated composites have fibres oriented only in the in-plane of the laminate due to their manufacturing process, and are therefore very susceptible to transverse cracking and delamination from out-ofplane actions. Delamination can considerably reduce the load bearing capacity of a structure hence several reinforcement solutions, based on the principle to add out-of-plane reinforcement to the 2D fabric, have been explored to enhance the delamination resistance. However, the usual textile technologies for Z-reinforcement such as weaving, knitting, stitching, z-pinning, and tufting generates perturbations that may alter the in-plane mechanical properties. Although tufting is a single needle and single thread based one side stitching (OSS) technique which can incorporate almost tension free through the thickness reinforcement in a material, various types of microstructural defects may be created during the manufacturing process and lead to a degradation of the in-plane properties of the composite. Moreover, due to awareness in environmental concerns, the development and use of eco-friendly biocomposites to replace synthetic ones has been increasing.

This research work investigates the effect on in plane mechanical properties of adding through the thickness reinforcement (TTR) by tufting in a flax based composite laminate to improve the transversal strength. The glass fibre tufted laminates of $550 \mathrm{~g} / \mathrm{m}^{2}$ flax fibre were moulded using a 38\% biobased thermoset resin by vacuum bag resin transfer moulding (VBRTM). The tufted and un-tufted in-plane mechanical properties of green biocomposite were determined in tension, compression and shear in accordance with ASTM 3039, ASTM D7137 and EN ISO 14130, using universal INSTRON 1186 and MTS 20 M testing machines. The quantification of the in-plane mechanical properties established a reduction of the in plane tensile mechanical properties, due to tufting, whereas the reduction effects are marginal in compression. As expected, the glass fibre tufts strength the connection between core and skin of the composite so that the interlaminar shear strength, deduced from flexural tests with small span-to-thickness ratio, is increased. Thanks to Digital Image Correlation (DIC) performed during shear tests, an increase in interlaminar shear modulus is highlighted.
\end{abstract}

Keywords: In-plane mechanical properties, Green biocomposites, Tensile, Shear, Compression

\footnotetext{
* Correspondence: madiha.rashid@insa-cvl.fr

${ }^{1}$ INSA Centre Val de Loire, Univ. Orléans, PRISME EA 4229, F-18022 Bourges,

France

Full list of author information is available at the end of the article
}

\section{Springer Open}

(c) The Author(s). 2021 Open Access This article is licensed under a Creative Commons Attribution 4.0 International License, which permits use, sharing, adaptation, distribution and reproduction in any medium or format, as long as you give appropriate credit to the original author(s) and the source, provide a link to the Creative Commons licence, and indicate if changes were made. The images or other third party material in this article are included in the article's Creative Commons licence, unless indicated otherwise in a credit line to the material. If material is not included in the article's Creative Commons licence and your intended use is not permitted by statutory regulation or exceeds the permitted use, you will need to obtain permission directly from the copyright holder. To view a copy of this licence, visit http://creativecommons.org/licenses/by/4.0/. 


\section{Introduction}

Fibre reinforced polymer (FRP) composites are in high demand for manufacturing structural components of automotive, aerospace, marine and wind energy sector. Despite high investment and manufacturing cost as compared to metallic alloys, the rapid growing interest in the use of FRPs has arisen due to promising properties, such as high strength to weight ratio, high specific stiffness, and excellent resistance to fatigue, creep, rapture and corrosion [1-3]. Additionally, the shift towards FRPs as lighter structural material is unavoidable to meet environmental targets of $75 \%$ and $90 \%$ reduction in the levels of $\mathrm{CO}_{2}$ and $\mathrm{NO}_{\mathrm{x}}$ by 2050 for which the contribution of airframes is evaluated from 20 to $25 \%$ [4]. Conventional composite laminates (2D) are very efficient in distributing inplane normal and shear loads since the alignment of fibres is along the load-bearing path. However, the lack of through the thickness reinforcing fibres is a disadvantage in terms of delamination toughness and impact damage resistance. Therefore, since the past four decades there has been a growing interest in the development of several methods in order to provide through-thickness strength and stiffness to preforms in the three-dimensional (3D) direction using through the thickness reinforcement techniques [5-9].

Among such developed methods, weaving, kitting, braiding were primarily used for manufacturing threedimensional preforms. However, these adopted processes from textile industry could not be used for a long period due to lack of flexibility of semi-finished products, costly and complex machinery, and inflexible machine parameters. Furthermore, the choice of adopting a particular process for fabricating 3D preform depends on the end use of product [10-17]. Although Mouritz presented large data base on the in-plane and out of plane mechanical properties of stitched 3D composites manufactured using various textile technologies, yet it is very difficult to conclude the best textile technology to reinforce through the thickness due to various technical, economic and certification issues [18]. In this scenario, stitching has been assessed as a potential technique for sewing through the laminate structure using a high tensile strength yarn, such as glass, carbon and kevlar [19]. Three-dimensional composite structures manufactured using stitched laminates have received considerable attention in high tech industry. Aircraft structure including large parts of airframe, wing panels, fuselages and blade-stiffened components are built using 3D composite materials [10]. It is also used in load bearing structure such as I-beam. In automotive industry it is used for manufacturing doorframe, bumper bar and floor panels [20].

Unfortunately, the manufacturing complexity of accessing the needle from downside to form the stitch and the resulting tension due to formation of loops and knots (chain stich and lockstitch) may degrade the in-plane mechanical properties especially bending and compression due to constrictions and undulations formed in the laminates [21, 22]. However, a variety of possible stitching parameters, such as type of needle, stitching material, stitching density, stitching geometry, stitching method, type of stitching, type of laminate, machine parameters, and thread tension makes it a highly flexible technology. Hence, keeping the pros of stitching technology in view, an extensive $R \& D$ is pursued to address the drawbacks of this technology to achieve desirable three-dimensional properties of a material without

a)

b)

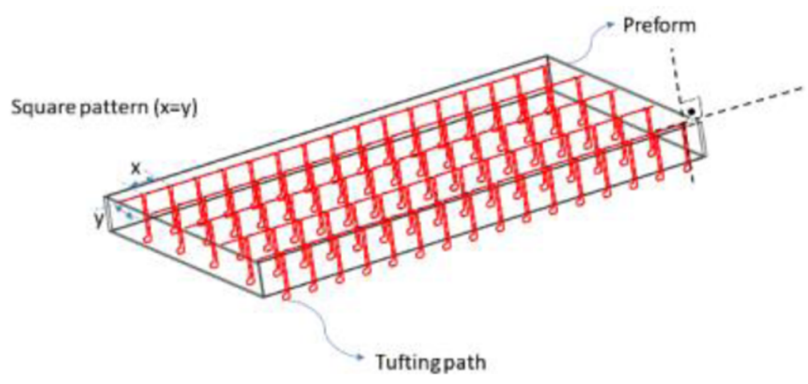

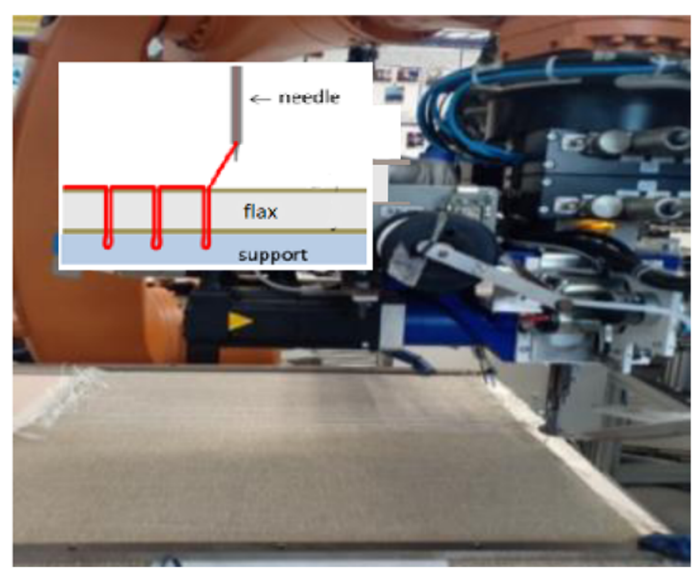

Fig. 1 a Schematic of transversal tufted specimens. b Tufting reinforcement in the Sheets of flax 


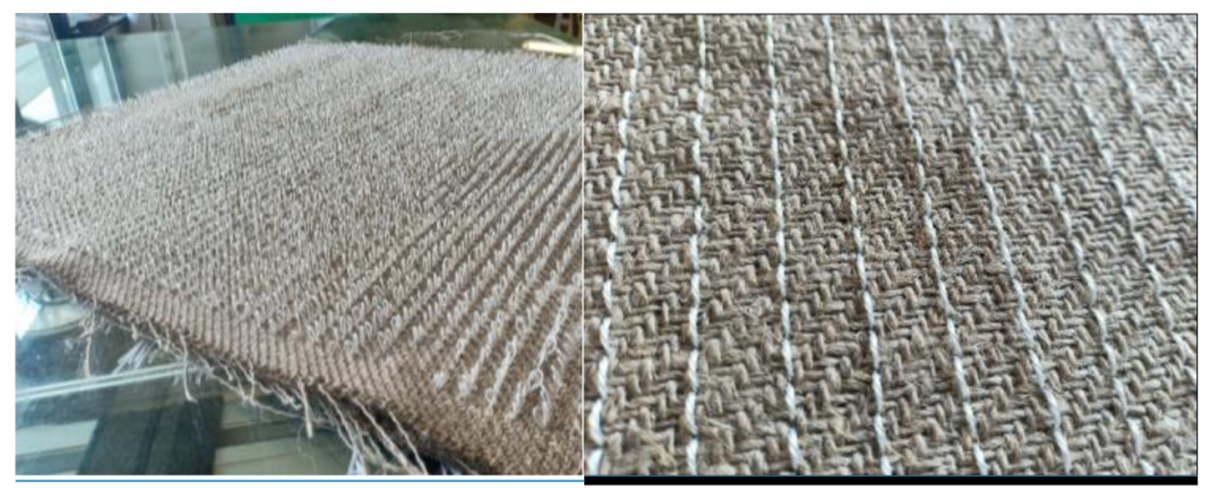

Fig. 2 Front and back of tufted sheets of flax

degrading the exceptional mechanical in-place properties.

In this regard, DLR Institute of Structural Mechanics at German Space Centre in Brunswick developed "Single-Sided Tufting Method" as the potential method to meet structural and cost effective efficiency requirements. Tufting was developed as the befitting structural stitching means to bring significant improvement in the energy absorption behaviours particularly the energy release rate, crack propagation, and damage tolerance [23]. In contrast to conventional stitching techniques that employ a dual threading system, "tufting" is a single thread method that makes tension free insertion of the thread needle in dry fabric laminates and removal of the needle from fabric laminates along the same trajectory $[24,25]$. In this process, loose and tension free loops form on the downward side without adversely affecting the laminates material. Furthermore, tufting is beneficial as compared to conventional stitching methods because the material to be sewn needs to be only accessible from one side therefore there would be no need of complex and costly construction with lift tables [26, 27].

It was realised by the authors after making a thorough literature review that there are few results related to the degree to which through-thickness reinforcement degrades in-plane mechanical properties of tufted fibre reinforced composites [1, 28-34] [35-37], and even fewer related to in-plane mechanical properties of tufted green biocomposites. Natural fibre based green biocomposites are the material of future in structural, automotive and aerospace industry due to their environmental merits, low density, high specific strength, stiffness, low energy consumption in fabrication, $\mathrm{CO}_{2}$ neutrality and sound proofing characteristics [38]. Since a degradation in the in-plane properties may arise due to local damage to fibres resulting from tufting needle, fibre kink and resin rich areas, this work presents the effect of tufting on the in-plane mechanical properties like tension, shear and compressive strengths of green biocomposites based on flax fibre reinforced with glass fibre tufts.

\section{Material and methodology for manufacturing green biocomposite \\ Materials}

The flax fibre was procured from Eco-technilin. It consists of $2 \times 2$ twill weave flax fibre with an areal

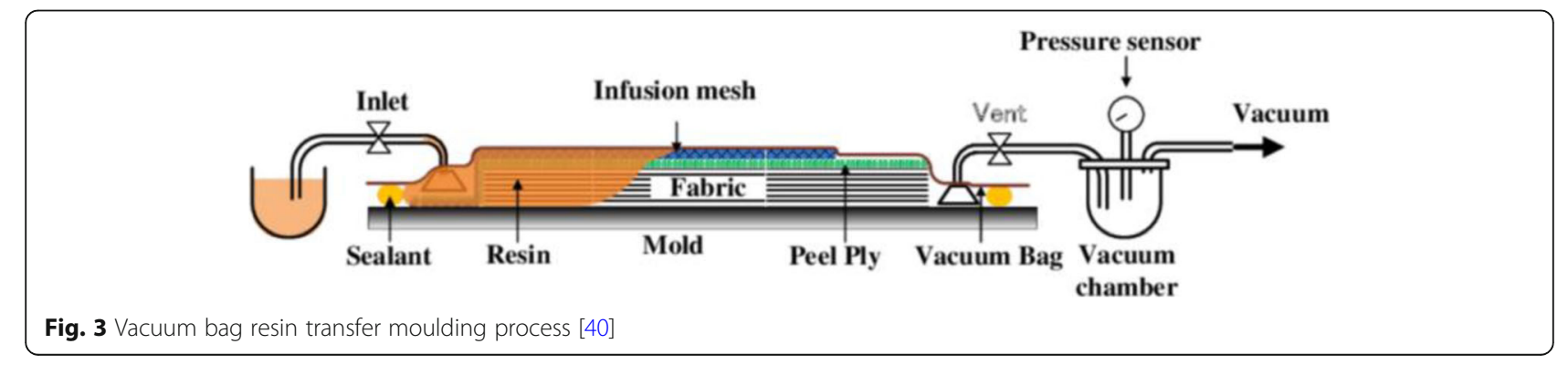




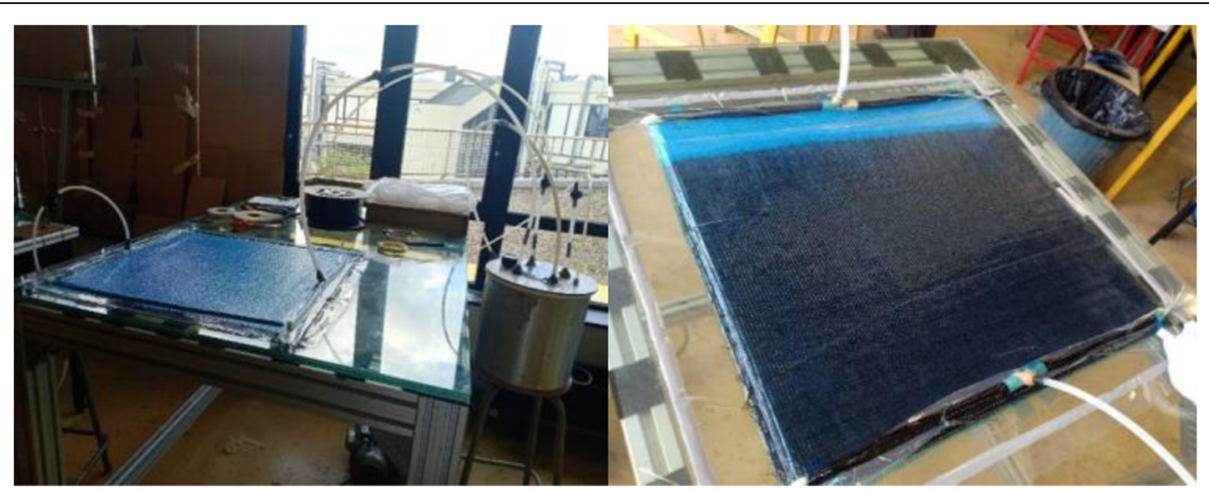

Fig. 4 Vacuum infusion process of flax fibre sheets

density of $550 \mathrm{~g} / \mathrm{m}^{2}$ and a linear density of $0.0045 \mathrm{~g} /$ $\mathrm{m}$. The epoxy resin used was InfuGreen 810 with SD 8822 curing agent, a 38\% biobased epoxy, procured from Sicomin. Glass fibre thread having a linear density of $0.179 \mathrm{~g} / \mathrm{m}$ and a twist level of 136 turns/m was supplied by Tissafil. KUKA 6-axis robot arm (KR 100-2 HA 2000) was employed to carry out tufting of six plies of flax fibre stacked on top of each other using glass fibre thread. The thread of glass fibre was inserted in a needle of 2 $\mathrm{mm}$ diameter to tuft the dry preform of flax fibre sheets [39]. The end tabs used to grip the specimen in tensile testing were fabricated by infusing InfuGreen 810 in bidirectional laminates of glass fibre.

\section{Methodology for manufacturing green biocomposite}

Six plies of flax fibre sheets were placed horizontally on top of each other with a stacking sequence of $[0]_{6}$ to manufacture the reference and tufted plates. The stitching process is characterised by insertion of glass fibre thread transversally by employing KUKA 6 -axis robot at $\pm 90^{\circ}$ to the normal plane of traditional 2D dry preform to reinforce flax fibre with a tufting density of $5 \times 5 \mathrm{~mm}$ in a transversal square geometry pattern as shown in Fig. 1 [40]. Once the tufting needle arrives at the selected depth, the needle is pulled back from dry preform, and a retention mechanism let the tufts to remain in the laminates. A ringlet is formed on the recto face of the 2D dry preform as shown in Fig. $2 \mathrm{a}$ and $\mathrm{b}$. The volume fraction of flax fibre reduces from $35 \%$ to $34.5 \%$ in tufted composite as compared the untufted one. The average length of tuft loops was fixed to $10 \mathrm{~mm}$ and a sheet of polyurethane form was placed as a support beneath the dry laminates of flax fibre sheets to hold the tuft loops of glass fibre and to keep them in place [31]. The areal density of untufted and tufted stacked preforms were estimated to be $2870 \mathrm{~g} /$ $\mathrm{m}^{2}$ and $3060 \mathrm{~g} / \mathrm{m}^{2}$ respectively.

The technique of vacuum bag resin transfer moulding process as shown in the schematic of Fig. 3 developed by Francis W. Bailey in 1996 was used to manufacture the green biocomposite using InfuGreen 810 epoxy resin system [41].

Figure 4 shows the moulding of flax fibre sheets performed under a vacuum pressure of -0.9 bar at room temperature. The infused plates were cured

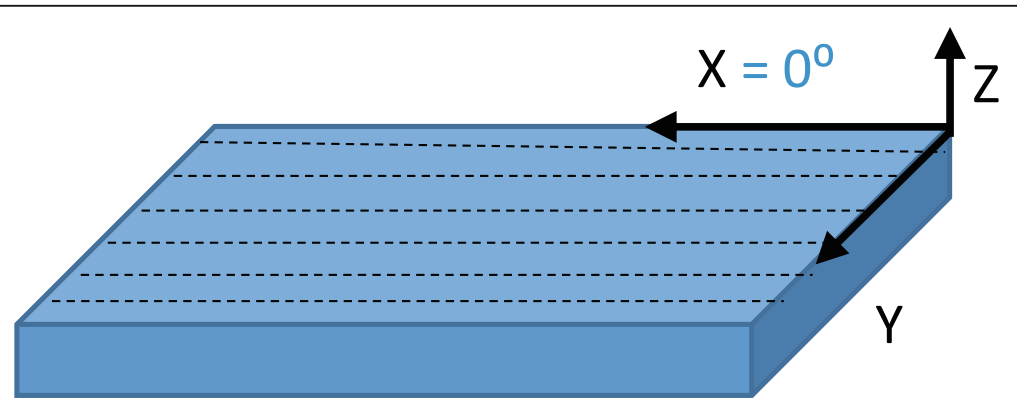

Fig. 5 Schematic of axis direction 

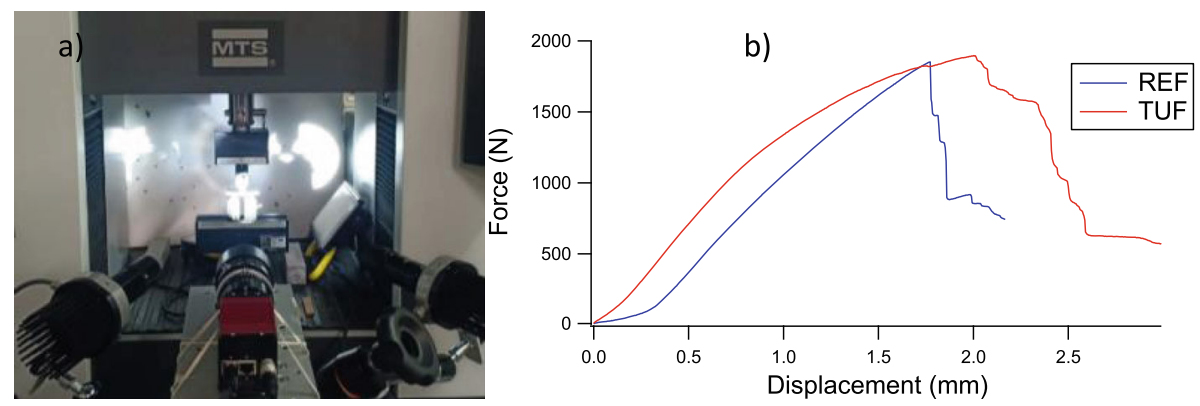

Fig. 6 a DIC carried out on short beam. b Load-Displacement curve of flexion for REF and TUF green biocomposite

for $24 \mathrm{~h}$ at room temperature and post cured in an oven for $8 \mathrm{~h}$ at $80^{\circ} \mathrm{C}$. The average final thickness of plates was estimated $6.5 \mathrm{~mm}$ for untufted and $7 \mathrm{~mm}$ for the tufted plates. A thickness of $0.5 \mathrm{~mm}$ was added in tufted plate due the presence of carbon tufts on the surface of flax sheets. The plates were cut to the specimens' size as per the requirements of ASTM or ISO standards for each mechanical test. The specimens are referred to as REF for nontufted and TUF for tufted in this study.

\section{Determination of in-plane mechanical properties}

The in-plane properties of tufted and untufted specimens were experimentally characterised in tension, compression, shear, and compared afterwards. The geometric specifications of the specimens were chosen according to the ASTM or ISO standards designated for each type of test. The experiments were conducted on a universal INSTRON 1186 for tensile and

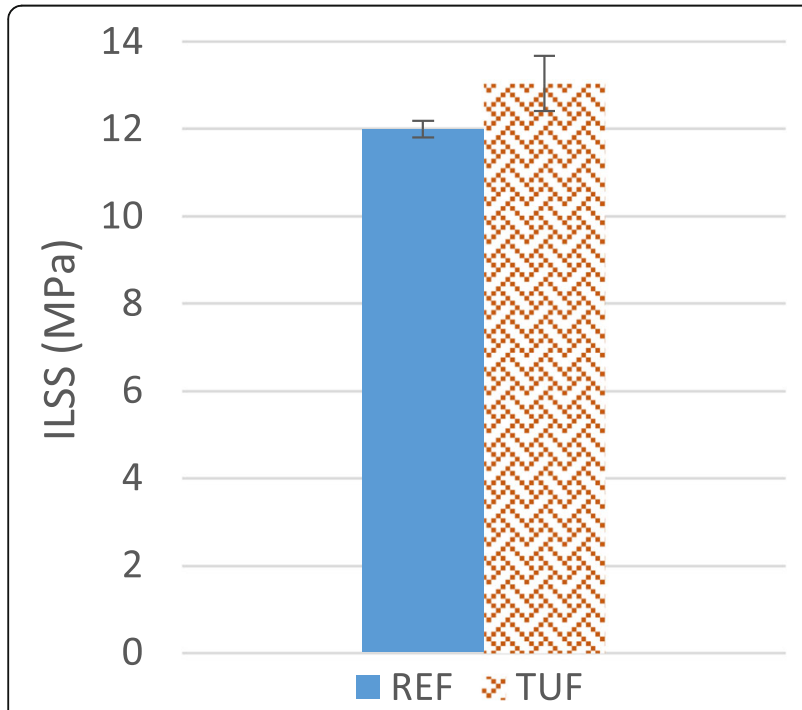

Fig. 7 Interlaminar shear strength for REF and TUF material compressive tests and on MTS $20 \mathrm{M}$ testing machines for short beam shear test.

\section{Three point bending-short beam shear test}

Short beam shear test is widely employed for screening and quality control of materials due to ease of sample preparation and testing [42]. The interlaminar shear properties of matrix obtained by short beam test provide important information on long-term degradation of the matrix [43-45].

The preparation of REF and TUF specimens and the procedure of carrying out three point bending test followed ASTM D2344-16 [46]. For the REF and TUF specimens, length and width were the same: $60 \mathrm{~mm}$ and $30 \mathrm{~mm}$ respectively, whereas the thickness for REF and TUF specimens was slightly different: $6.5 \mathrm{~mm}$ and $7 \mathrm{~mm}$ respectively. The loading configuration was defined by a span length of $32 \mathrm{~mm}$, support cylinder diameter of $3 \mathrm{~mm}$ and loading nose diameter of $6 \mathrm{~mm}$. A Digital imaging camera (DIC) was placed in front of loaded specimens to perform in situ non-destructive testing and to capture the images during tests. The specimens of three point bending tests were analysed with scanning electron microscope (SEM) to observe the pattern of crack propagation.

\section{Boeing compression test}

Boeing compression test (BCT) are performed to evaluate the effect of tufting on the in-plane compressive strength of composites while preventing buckling. The specimens were prepared according to ASTM D7137-07 [47] and universal testing machine was employed to perform BCT following modified D695 compression test method [48]. The length and width of specimens for BCT were $150 \mathrm{~mm}$ and 100 $\mathrm{mm}$ respectively for both REF and TUF materials, and the thicknesses of samples were $6.5 \mathrm{~mm}$ for REF and $7 \mathrm{~mm}$ for TUF material. Three specimens of 


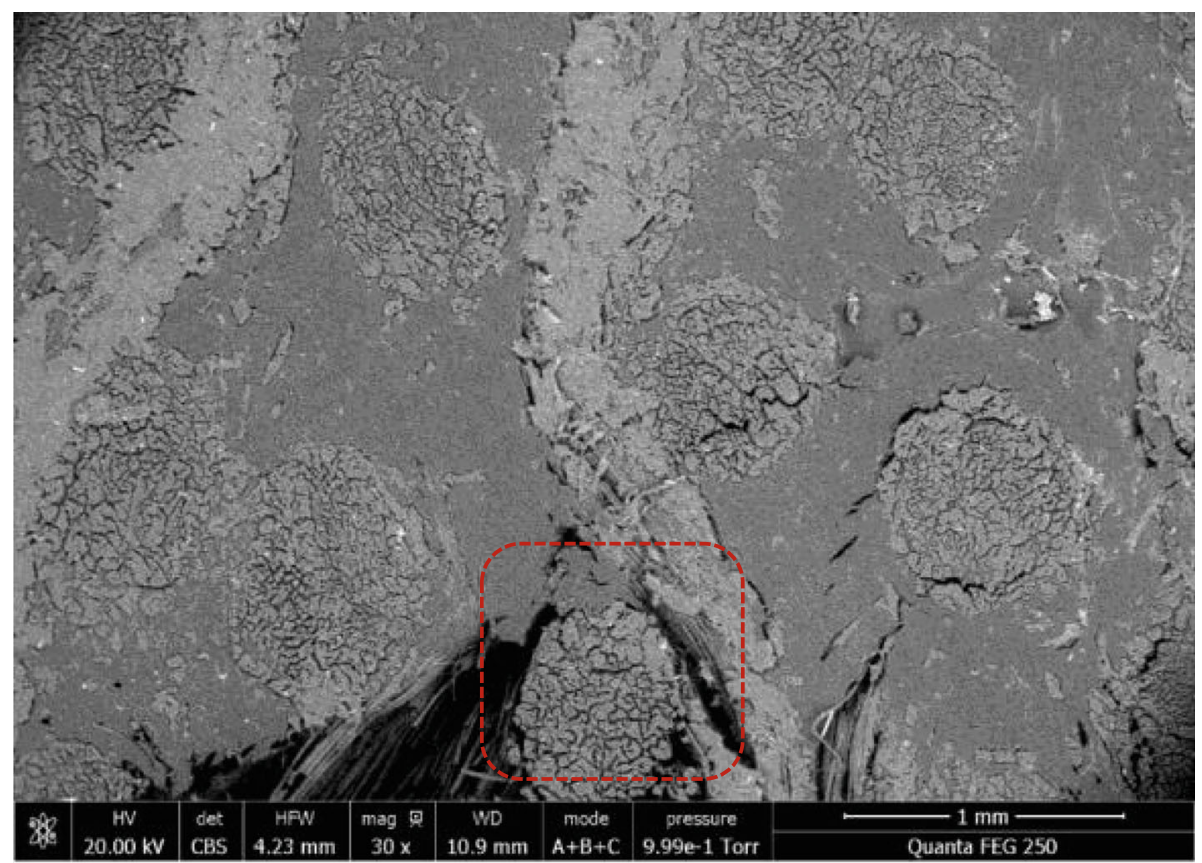

Fig. 8 Observation of crack propagation around a stitch using SEM

each i.e. REF and TUF were subjected to BCT loading to calculate ultimate compressive strength and compression modulus.

\section{Tensile test}

Tensile strength test is used to determine the inplane properties of composites materials. However, this test is limited to such polymer matrix composites that are reinforced with high modulus fibre, and where the laminates are symmetric and balanced with respect to the test direction. The tensile property data produced from this test is extensively used for quality assurance, and structural design and analysis.

The tensile test was carried out on a universal testing machine as per the ASTM standard D3039/ $3039 \mathrm{M}-17$ [49]. The rectangular specimens of REF and TUF had a length of $200 \mathrm{~mm}$ and width of 35 $\mathrm{mm}$, whereas the thickness of REF material was 6.5 $\mathrm{mm}$ and for TUF was $7 \mathrm{~mm}$. To prevent failure in the grip while performing the tensile test, $40 \mathrm{~mm}$ tabs made up of glass fibre and InfuGreen 810 epoxy were attached on each end of the specimen. To measure the values of Young's modulus and ultimate tensile strength strain gauge was placed in the centre of specimen. The load was applied to the specimen at a constant rate of $1 \mathrm{~mm} / \mathrm{min}$ until the specimen fractured.

\section{Results and discussion}

The in-plane mechanical properties of tufted and untufted biocomposite samples were compared for tensile, compressive and shear strength of the material. The Investigation of tufting behaviour with respect to control specimen on the shear loading conditions was carried out on REF and TUF samples. Figure 5

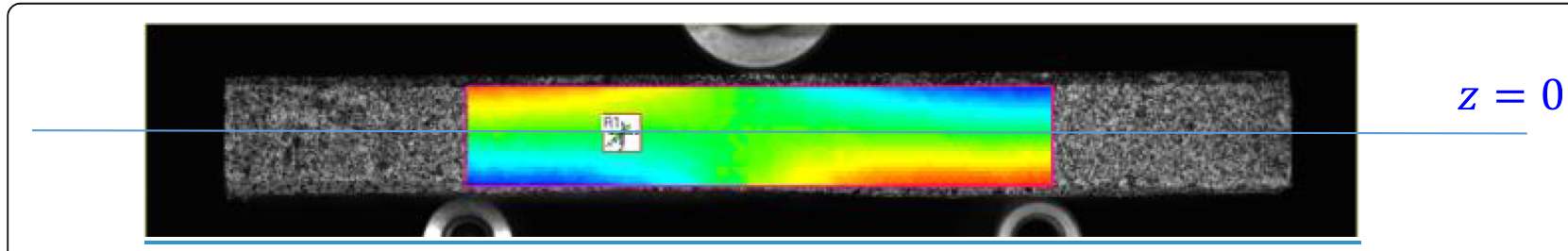

Fig. 9 Virtual gage positioned on DIC longitudinal displacement field to calculate the mean strain 

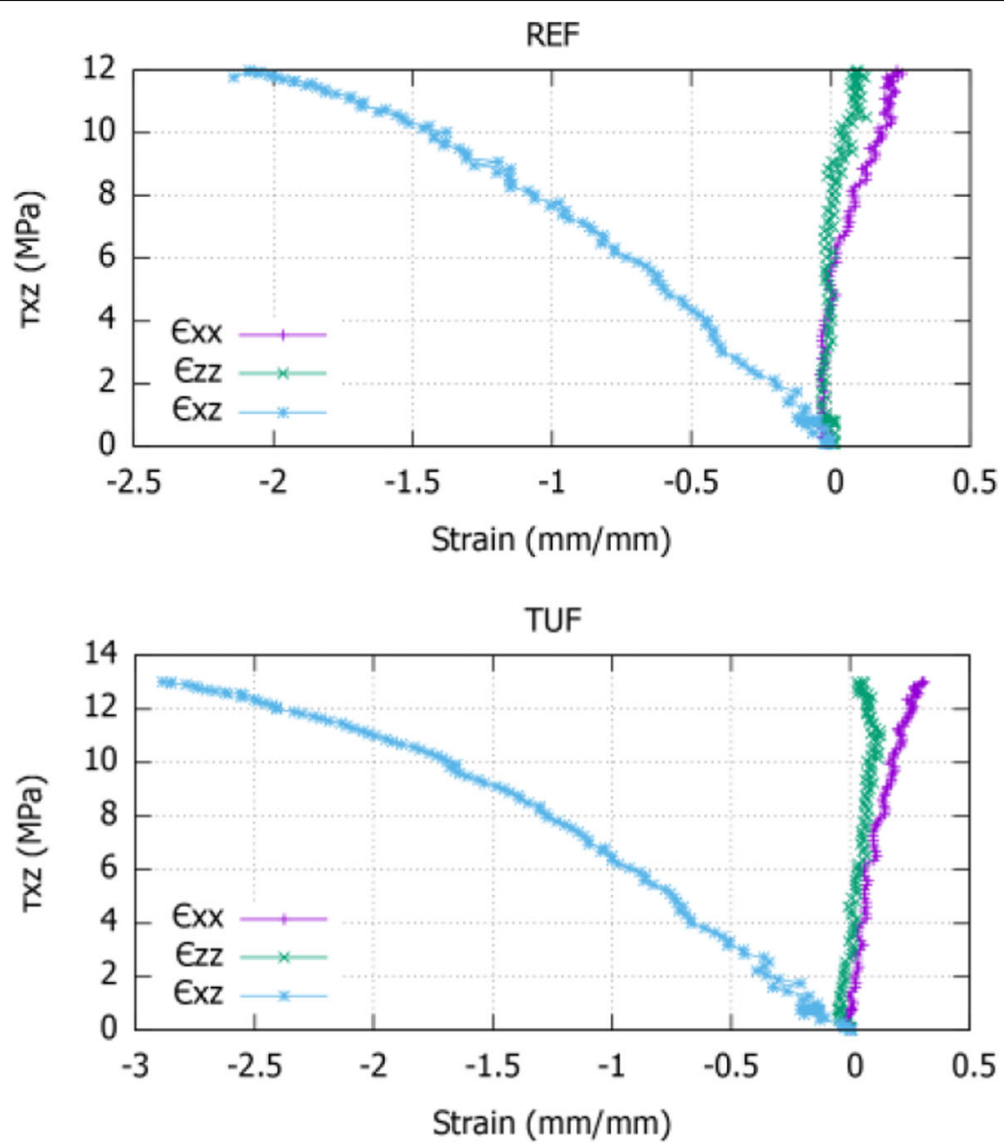

Fig. 10 Mean strains ( $\varepsilon X X, \varepsilon z z$, and $\varepsilon X z)$ obtained by DIC images from REF and TUF specimens

represents a schematic of the direction of axis used in this study.

Short beam bending tests were conducted in order to compare these two materials in terms of interlaminar shear behaviour. Figure $6 \mathrm{~b}$ displays the typical global response of the specimens subjected to the short beam shear tests.

For a linearly elastic beam with a rectangular cross section of width $b$ and depth $h$, a parabolic stress distribution is assumed. This result is demonstrated with the

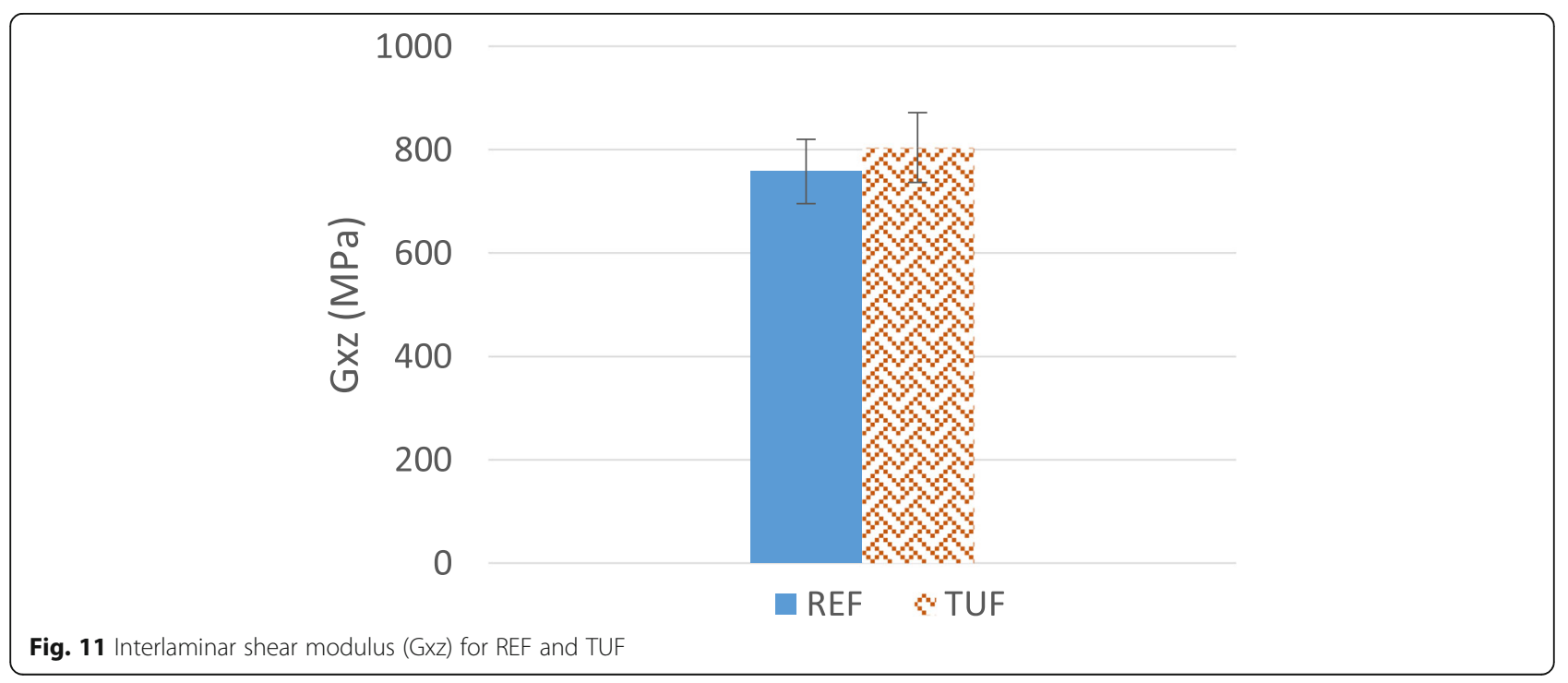


Table 1 Interlaminar shear strength and flexural modulus of REF and TUF biocomposite

\begin{tabular}{lll}
\hline Specimen & Interlaminar shear strength (MPa) & Shear modulus (MPa) \\
\hline REF & $11.98 \pm 0.18$ & $758 \pm 62.27$ \\
TUF & $13.03 \pm 0.63$ & $804 \pm 67.37$
\end{tabular}

use of the first kinematic Euler-Bernouilli assumption, which states that the cross-section of the beam remains plane after deformation, and on the meeting of equilibrium conditions. The shear stress distribution in terms of the applied shear force, $V=\frac{P}{2}$ where $\mathrm{P}$ is the load in Newton $(\mathrm{N})$, is:

$$
\tau_{x z}=\frac{3 V}{2 b h}\left[1-\left(\frac{2 z}{h}\right)^{2}\right]
$$

This assumption has been found to be valid for large parts of the beam between the loading and supporting rollers, especially for large loading roller diameter [50].

The maximum shear stress, found at the neutral axis $(z=0)$, shows the interlaminar shear strength $\left(\tau_{x z}\right)$ of the composite material that is reported in ISO 14130 or ASTM D2344-16. It is represented by eq. (2).

$$
\tau_{x z}=\frac{3}{4} \frac{P}{b \times h}
$$

The maximum interlaminar shear strength (ILSS) of the REF and TUF material shown in Fig. 7 exhibits that tufting reinforcement increases shear strength of the flax fibre based green biocomposite by $8 \%$. The literature review reports conflicting results [51-56] i.e. the stitches can become sites of stress concentration that can cause reduction in the interlaminar shear strength whereas the improvement in shear strength is possibly due to throughthickness interlocking which difficult shearing between the fabric plies. Microscopic observation of the specimen after short beam shear test was performed using SEM. It is shown in Fig. 8 how tufts arrests crack propagation in the tufted material. The specimen is loaded by shear force parallel to crack surfaces. The sliding of crack surfaces over each other in the $\mathrm{x}$ direction results in a skew symmetric deformation with respect to the plane i.e. perpendicular to the $\mathrm{y}$ and $\mathrm{z}$ axis. Delamination starts from the resin pocket on the outside region but the tufted thread arrests its propagation and improves fracture toughness of the materials. The bridging effect of tufts enhances local stiffness by precluding the sliding of inter-plies $[57,58]$.

Digital Image Correlation performed for three point bending short beam shear test, as shown in Fig. 6a, was used to calculate mean shear strain $\left(\gamma_{x z}\right)$ and in turn interlaminar shear modulus $\left(G_{x z}\right)$. As the shear stress is to be maximum on neutral plane (eq. (2)), to efficiently achieve the interlaminar shear strain, a small area centred in neutral plane $(z=0)$ was selected as shown in Fig. 9. To be consistent with the assumption of a parabolic shear stress distribution, this zone must be sufficiently far from the support and loading rollers and exhibit negligible principal strains $\left(\varepsilon_{\mathrm{xx}}\right.$ and $\left.\varepsilon_{\mathrm{zz}} \approx 0\right)$.
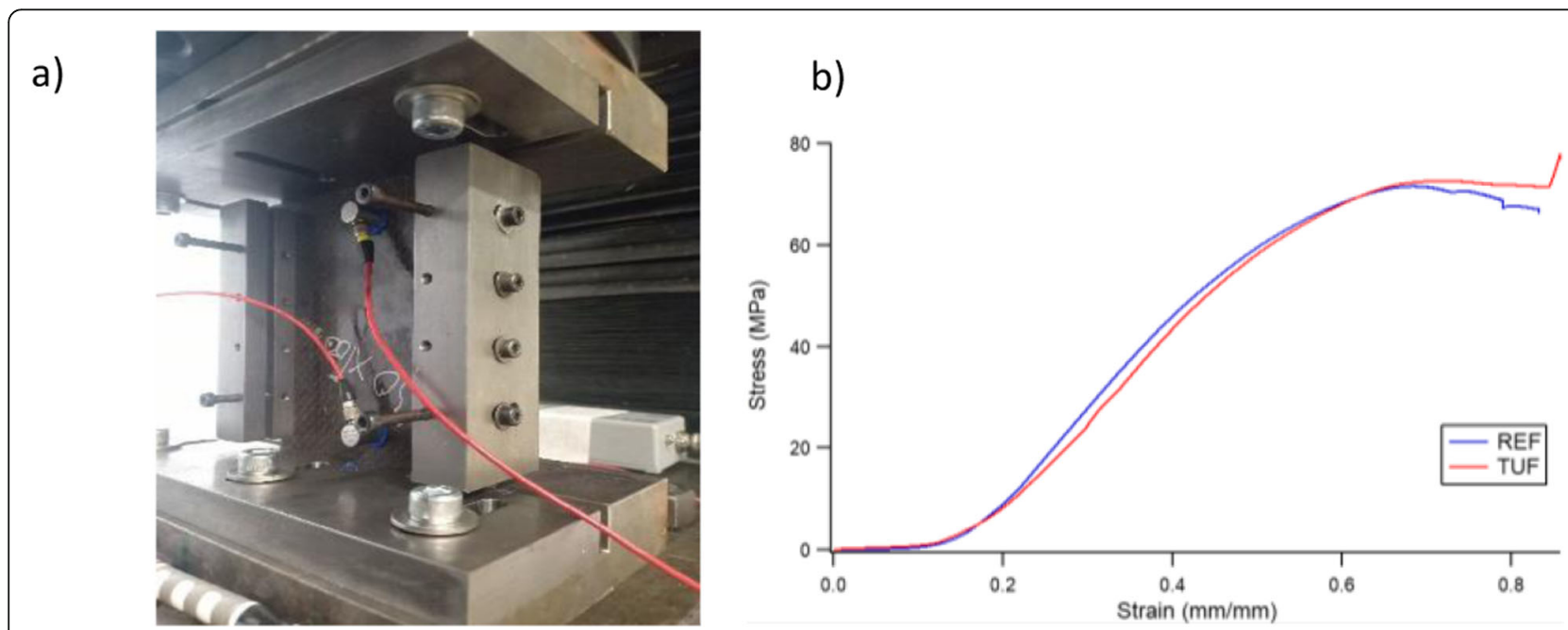

Fig. 12 a) Specimen in loading under compression b) Stress-Strain curve of REF and TUF green biocomposite 
Table 2 Ultimate compressive strength and compressive modulus of REF and TUF green biocomposite

\begin{tabular}{llll}
\hline Specimen & Ultimate compressive strength (MPa) & Compressive modulus (GPa) & Strain (dX) \\
\hline REF & $71.5 \pm 5.38$ & $0.194 \pm 0.016$ & 0.132 \\
TUF & $72.4 \pm 4.32$ & $0.190 \pm 0.029$ & 0.108
\end{tabular}

The virtual gauge was positioned in different places for different specimen since Song [59] has reported that for tufted specimen the mean shear strain differs considerably for a region containing tuft thread as compared to a region not including a tuft thread. Therefore, to homogenise the properties of the biocomposite material the choice of positioning the gauge must be carefully selected including the fabric preform and tufting thread.

Using DIC and virtual strain gauge rosettes gives us access to the longitudinal strain $\left(\varepsilon_{\mathrm{xx}}\right)$, out ofplane strain $\left(\varepsilon_{\mathrm{zz}}\right)$ and interlaminar shear strain $\left(\varepsilon_{\mathrm{xz}}\right)$ at any moment of the loading. These values, synchronised with the interlaminar shear (eq. (2)), are shown in Fig. 10.

The linear part in the interlaminar shear stressstrain curve in Fig. 10 gives the interlaminar shear moduli for REF and TUF samples. The interlaminar shear moduli of tufted specimens of flax based green biocomposite increases slightly by $5.7 \%$ (Fig. 11) as compared to untufted material. The values of interlaminar shear strength and shear modulus are reported in Table 1.

Boeing Compression test was performed to determine the compressive strength of the flax based green biocomposite materials. Three samples of each REF and TUF were subjected to compression loading as shown in Fig. 12a, and the linear part of the stress strain curve of Fig. $12 \mathrm{~b}$ is used to calculate the compressive modulus. The results of ultimate compressive strength and compressive modulus are presented in Table 2 .
The results shown in Fig. 13a and b highlights that through the thickness reinforcement marginally improves the ultimate strength of the material. It is reported in a number of paper that tufting does not significantly affect the compressive strength of the fibre-reinforced composites [22, 52, 60-70]. Dow and smith [63] reported similar compressive strengths of carbon fibre reinforced polymer (CFRP) stitched with either glass, carbon or Kevlar ${ }^{\circledR}$ as compared to their unstitched counterpart [71]. Harris et al. [60] and Herzberg and Bannister [72] found similar behaviour of stitched and unstitched CFRP. Similarly, Du et al. [52] also did not observe any appreciable change to the compressive strength of CFRP after stitching with Kevlar .

During the tensile tests, the values of load, displacement, strain and time were measured throughout the test as shown in Fig. 14a. The gradient of the linear part of stress-strain curve shown in Fig. 14b gives the Young's modulus of the material and the ultimate tensile strength is determined from the failure load. The results are displayed in Table 3 .

It can be seen in Fig. 15 that the Young's modulus and ultimate tensile strength are reduced by $42 \%$ and $31 \%$ respectively.

Reduction of the in-plane tensile properties could be due to misalignments and fibre rupture caused by tufting of laminated composite and concentration of stress around tufts [73]. Furthermore, tufting loops accumulate a thin layer of resin that gives rise to the thickness of sample. The formation of a thin layer of
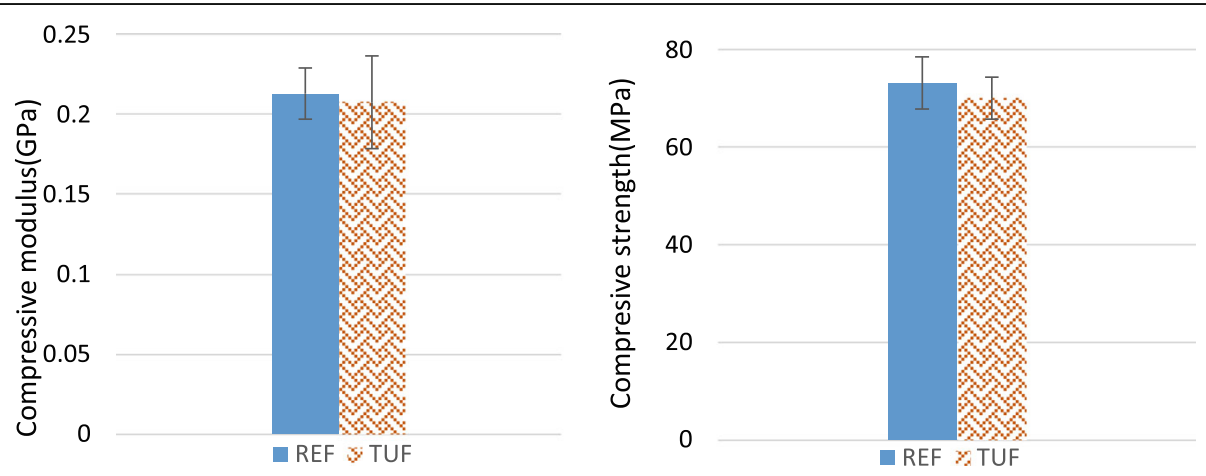

Fig. 13 a Ultimate compressive strength and $\mathbf{b}$ Compressive modulus for REF and TUF green biocomposite 


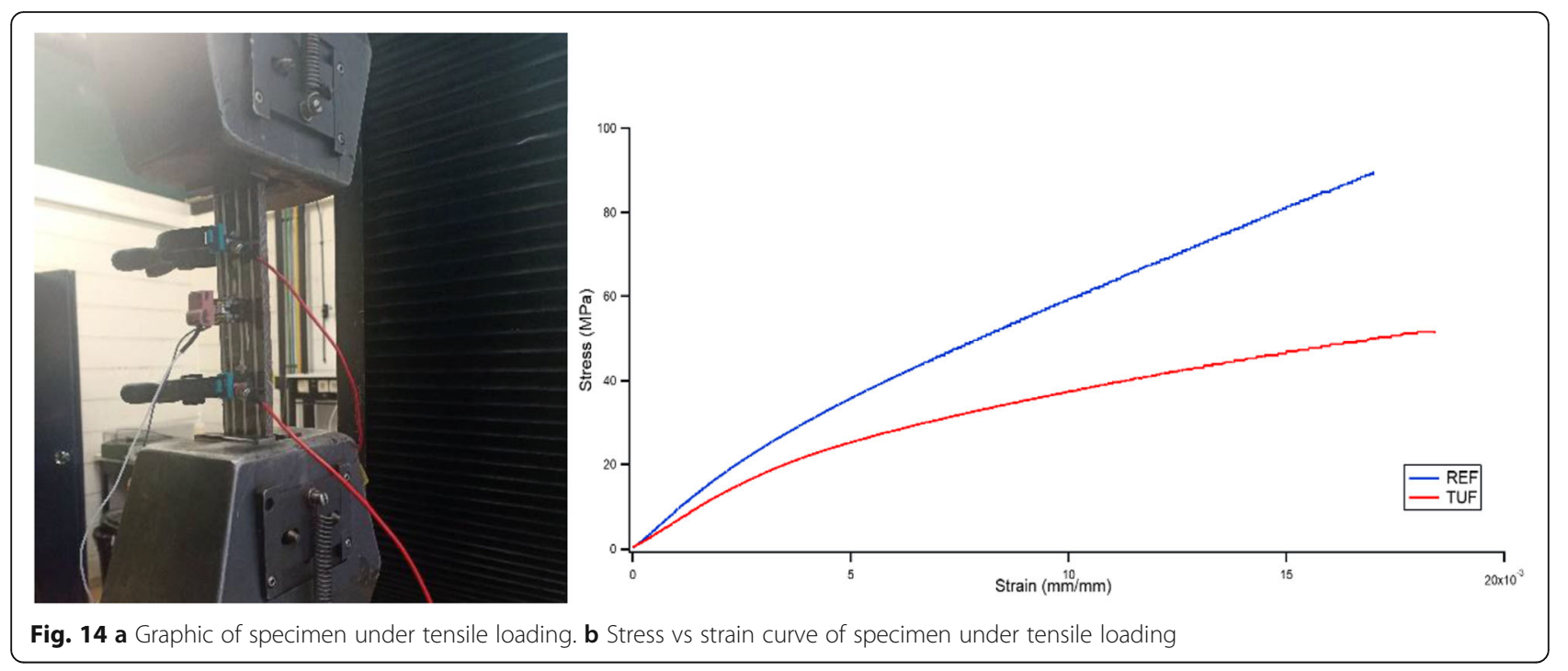

Table 3 Young's modulus and Ultimate tensile strength of REF and TUF green biocomposite

\begin{tabular}{llll}
\hline Specimen & Young's Modulus (GPa) & Ultimate tensile strength $(\mathbf{M P a})$ & Strain $(\mathbf{d X})$ \\
\hline REF & $8.97 \pm 0.23$ & $89.67 \pm 1.33$ & 0.0015 \\
TUF & $6.12 \pm 0.19$ & $51.67 \pm 2.39$ & 0.0014 \\
\hline
\end{tabular}

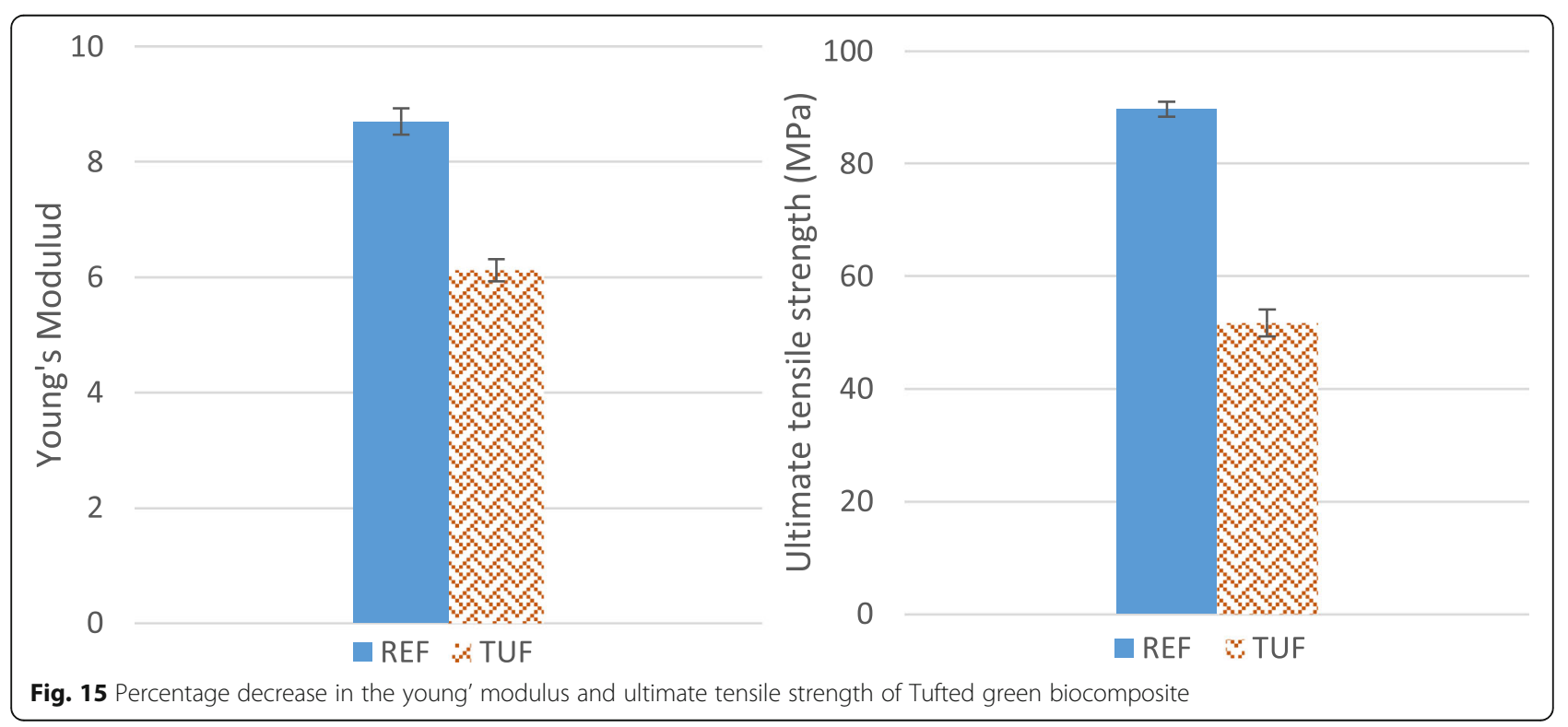




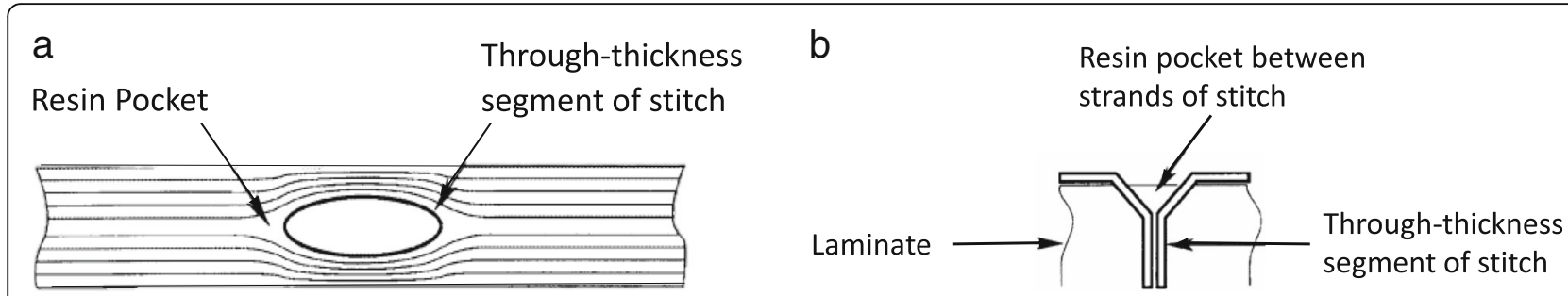

Fig. 16 Schematic of stitching defects [20] a) in-plane fibres misalignment, $\mathbf{b}$ resin pocket created on the laminate surface between the stitched threads

resin, with a low mechanical resistance, increases the cross section of material and thereby the strength of sample is reduced. Tufting changes the original architecture of the twill weave and form misaligned fibres as shown in Fig. 16a, it can be seen in the figure that glass fibre thread has moved the tows of flax fibre sideways causing a misalignment.

This created space between the misaligned flax fibres and glass thread can be permeated with resin as shown in Fig. 16b. These two defects caused by tufting, i.e. fibre misalignment and resin rich region are mainly responsible for reduced in-plane properties reported in tensile testing of flax based green biocomposite [74].

\section{Conclusion}

This study deals with the effect of tufting on the in-plane mechanical properties and failure mechanisms of structurally tufted flax and its non-tufted counterpart loaded in tension, compression and shear. The distortion induced by glass fibre during tufting yields negative effect on the in-plane mechanical properties of the green biocomposite in tension, the effects are marginal in compression, whereas in shear a slight improvement in interlaminar shear strength and shear modulus is reported. It is essential to mention that there are only few similar studies on the characterisation of in-plane mechanical properties of green biocomposite composed of natural fibre and a bioepoxy resin. The reduction in the values of Young's modulus of specimen in tension is certainly due to the distortion of in-plane fibres around the tufts that leads to their misalignment with the load applied and the formation of resin rich pockets. When the biocomposite tufted with a yarn of high modulus, such as glass, is loaded in compression, the failure due to Euler buckling is inhibited. However, tufted laminates of flax fail in compression by the formation of kink bands around the most distorted fibres [20]. This mechanism is considered to be primarily responsible for the marginal reduction in compressive modulus. In case of short beam shear test, tuft threads are responsible for concentration of stress, which leads to commencement of cracks from them and result in interlaminar propagation until they are arrested by the next tuft row. This crack bridging phenomenon and difficulty in shearing between plies is thought to improve the ILSS of the tufted material. The finding of this study reveals the complexity of reinforcing biocomposites in through the thickness direction. Hence, to improve their performance rigorous efforts are required in order to take the understanding of mechanical behaviour of $3 \mathrm{D}$ biocomposites to the level of understanding of mechanical behaviours of 2D laminated composites.

\section{Abbreviations}

BCT: Boeing compression test; CFRP: Carbon fibre reinforced polymer; DIC: Digital image correlation; FRP: Fibre reinforced polymer;

ILSS: Interlaminar shear strength; OSS: One side stitching; REF: Reference; SEM: Scanning electron microscope; TTR: Through the thickness

reinforcement; 3D: Three-dimensional; TUF: Tufted; VBRTM: Vacuum bag resin transfer moulding

\section{Acknowledgements}

The authors appreciate the generosity of Mr. Muddassir Abrar to perform a thorough reading of the paper several times to avoid any mistakes of language and citations, and for checking the coherence of the work in the manner, it is presented.

\section{Authors' contributions}

MR selected the materials used in this study and manufactured the green biocomposite using flax fibre and InfuGreen 810 epoxy through VBRTM. She prepared the samples according to ASTM standards for testing of in-plane mechanical properties. She performed the tensile, bending and compression tests and analysed the results. She wrote the first draft of article, which kept, on improving with the input of other authors and she finalised the final version of the article presented here. J.LH carried out the three point bending test and Digital imaging correlation of the materials. He analysed the results of three point bending test, and contributed in writing the results of three point bending test. He did a thorough internal review of the article as well. KC supervised the study. He managed the procurement of the material used in this study and provided guidelines on selection of material for this study. He monitored the various steps involved during this study and contributed in internally reviewing the article at several stages. KK guided and helped in manufacturing of the green biocomposite. He was also involved in providing guidelines on performing the in-plane mechanical test correctly. He prepared the tabs used in tensile testing of the material. He provided his input in analysing the results of tensile and compression tests. ZA provided guideline in procurement of natural fibre for this study. He carried out the tufting of the material and provided guideline on carrying out tensile, bending and compression test according to specified ASTM standards. NG supervised the study. He did an internal review of the paper. He provided his input in analysing the results of in-plane mechanical properties and SEM analysis. The authors read and approved the final manuscript. 


\section{Funding}

Higher Education Commission, Pakistan.

\section{Availability of data and materials}

All data generated or analysed during this study are included in this published article.

\section{Declarations}

\section{Competing interests}

The authors declare that they have no competing interests.

\section{Author details}

${ }^{1}$ INSA Centre Val de Loire, Univ. Orléans, PRISME EA 4229, F-18022 Bourges, France. ${ }^{2}$ INSA Centre Val de Loire, Univ. Orléans, Univ. Tours, LaMé, EA 7494 F-18022 Bourges, France. ${ }^{3}$ Laboratoire Roberval, Université de Technologie de Compiègne, UMR-CNRS 7337 Centre de Recherche de Royallieu, 60203 Compiègne, France.

Received: 20 November 2020 Accepted: 23 February 2021 Published online: 08 April 2021

\section{References}

1. I. Gnaba, X. Legrand, P. Wang, D. Soulat, Through-the-thickness reinforcement for composite structures: A review. J. Ind. Text. 49, 71-96 (2019). https://doi.org/10.1177/1528083718772299

2. I. Baran, K. Cinar, N. Ersoy, R. Akkerman, J.H. Hattel, A review on the mechanical modeling of composite manufacturing processes. Arch. Comput. Methods Eng. 24, 365-395 (2017). https://doi.org/10.1007/s11831 016-9167-2

3. C. Zweben, in Mech. Eng. Handb. Composite Materials (American Cancer Society, 2015), pp. 1-37. https://doi.org/10.1002/9781118985960.meh110

4. A. Garcia, B. Bettignies-Thiébaux, Beyond vision 2020 (towards 2050). Aeronaut. Air Transp. Beyond Vis. 2020, 1-100 (2010)

5. P. Potluri, P. Hogg, M. Arshad, D. Jetavat, P. Jamshidi, Influence of fibre architecture on impact damage tolerance in 3D woven composites. Appl. Compos. Mater. 19, 799-812 (2012). https://doi.org/10.1007/s10443-012-92 56-9

6. F. Dau, M.-L. Dano, Y. Duplessis Kergomard, Experimental investigations and variability considerations on 3D interlock textile composites used in low velocity soft impact loading. Compos. Struct. 153, 369 (2016). https://doi. org/10.1016/j.compstruct.2016.06.034

7. K. Warren, R. Lopez-Anido, J. Goering, Experimental investigation of threedimensional woven composites. Compos. Part A Appl. Sci. Manuf. 73, 242259 (2015). https://doi.org/10.1016/j.compositesa.2015.03.011

8. G.A. Bibo, P.J. Hogg, The role of reinforcement architecture on impact damage mechanisms and post-impact compression behaviour. J. Mater. Sci. 31, 1115-1137 (1996). https://doi.org/10.1007/BF00353091

9. W.J. Cantwell, J. Morton, The impact resistance of composite materials - A review. Composites. 22, 347-362 (1991). https://doi.org/10.1016/0010-4361 (91)90549-V

10. A.P. Mouritz, M.K. Bannister, P.J. Falzon, K.H. Leong, Review of applications for advanced three-dimensional fibre textile composites. Compos. Part A Appl. Sci. Manuf. 30, 1445-1461 (1999). https://doi.org/10.1016/S1359-83 5X(99)00034-2

11. K. Bilisik, Three-dimensional braiding for composites: A review. Text. Res. J. 83, 1414-1436 (2012). https://doi.org/10.1177/0040517512450766

12. S. Chou, H.-E. Chen, The weaving methods of three-dimensional fabrics of advanced composite materials. Compos. Struct. 33, 159-172 (1995). https:// doi.org/10.1016/0263-8223(95)00120-4

13. L. Lee, Effect of weaving damage on the tensile properties of threedimensional woven composites. Compos. Struct. 57, 405-413 (2002)

14. L. Ciobanu, Development of 3D Knitted Fabrics for Advanced Composite Materials (2011). https://doi.org/10.5772/14876

15. N. Padaki, A. Ramasamy, S. Sridharan, Knitted preforms for composite applications. J. Ind. Text. 35, 295-321 (2006). https://doi.org/10.1177/152 8083706060784

16. K.A. Dransfield, L.K. Jain, Y.-W. Mai, On the effects of stitching in CFRPs-I. mode I delamination toughness. Compos. Sci. Technol. 58, 815-827 (1998). https://doi.org/10.1016/S0266-3538(97)00229-7
17. N. Zhao, H. Rödel, C. Herzberg, S.-L. Gao, S. Krzywinski, Stitched glass/PP composite. Part I: Tensile and impact properties. Compos. Part A Appl. Sci. Manuf. 40, 635-643 (2009). https://doi.org/10.1016/j.compositesa.2009.02.019

18. A.P. Mouritz, in Compos. Reinf. Optim. Perform, ed. by P. Boisse. 6 - threedimensional (3D) fibre reinforcements for composites (Woodhead Publishing, 2011), pp. 157-199. https://doi.org/10.1533/9780857093714.2.157

19. K. Dransfield, C. Baillie, Y.-W. Mai, Improving the delamination resistance of CFRP by stitching-A review. Compos. Sci. Technol. 50, 305-317 (1994). https://doi.org/10.1016/0266-3538(94)90019-1

20. A.P. Mouritz, B.N. Cox, A mechanistic approach to the properties of stitched laminates. Compos. Part A Appl. Sci. Manuf. 31, 1-27 (2000). https://doi. org/10.1016/S1359-835X(99)00056-1

21. G.L. Farley, A mechanism responsible for reducing compression strength of through-the-thickness reinforced composite material. J. Compos. Mater. 26, 1784-1795 (1992). https://doi.org/10.1177/002199839202601206

22. G.L. Farley, L.C. Dickinson, Removal of surface loop from stitched composites can improve compression and compression-after-impact strengths. J. Reinf. Plast. Compos. 11, 633-642 (1992). https://doi.org/10.11 77/073168449201100604

23. M. Karahan, Y. Ulcay, R. Eren, N. Karahan, G. Kaynak, Investigation into the tensile properties of stitched and unstitched woven aramid/vinyl Ester composites. Text. Res. J. 80, 880-891 (2010). https://doi.org/10.1177/004051 7509346441

24. C. Scarponi, A.M. Perillo, L. Cutillo, C. Foglio, Advanced TाT composite materials for aeronautical purposes: Compression after impact (CAl) behaviour. Compos. Part B Eng. 38, 258-264 (2007). https://doi.org/10.1016/ j.compositesb.2006.03.014

25. A.R. Mills, J. Jones, Investigation, manufacture, and testing of damageresistant airframe structures using low-cost carbon fibre composite materials and manufacturing technology. Proc. Inst. Mech. Eng. Part G J. Aerosp. Eng. 224, 489-497 (2010). https://doi.org/10.1243/09544100JAERO573

26. C. Sickinger, A. Herrmann, Structural Stitching as a Method to Design HighPerformans Composites in Future (2001)

27. A. Ogale, C. Weimer, P. Mitschang, Selection of sewing threads for preform manufacturing. Adv. Compos. Lett. 13, 096369350401300304 (2004). https:// doi.org/10.1177/096369350401300304

28. A. Henao, M. Carrera, A. Miravete, L. Castejón, Mechanical performance of through-thickness tufted sandwich structures. Compos. Struct. 92, 20522059 (2010). https://doi.org/10.1016/j.compstruct.2009.11.005

29. L. Liu, T. Zhang, P. Wang, X. Legrand, D. Soulat, Influence of the tufting yarns on formability of tufted 3-dimensional composite reinforcement. Compos. Part A Appl. Sci. Manuf. 78, 403-411 (2015). https://doi.org/10.101 6/j.compositesa.2015.07.014

30. G. Dell'Anno, J.W.G. Treiber, I.K. Partridge, Manufacturing of composite parts reinforced through-thickness by tufting. Robot. Comput. Integr. Manuf. 37, 262-272 (2016). https://doi.org/10.1016/j.rcim.2015.04.004

31. J.W. Hartley, J. Kratz, C. Ward, I.K. Partridge, Effect of tufting density and loop length on the crushing behaviour of tufted sandwich specimens. Compos. Part B Eng. 112, 49-56 (2017). https://doi.org/10.1016/j.compositesb.2016.12. 037

32. D.D.R. Cartié, G. Dell'Anno, E. Poulin, I.K. Partridge, 3D reinforcement of stiffener-to-skin T-joints by Z-pinning and tufting. Eng. Fract. Mech. 73, 2532-2540 (2006). https://doi.org/10.1016/j.engfracmech.2006.06.012

33. G. Pappas, S. Joncas, V. Michaud, J. Botsis, The Influence of ThroughThickness Reinforcement Geometry and Pattern on Delamination of FiberReinforced Composites: Part I - Experimental results. Compos. Struct. 184, 924 (2017). https://doi.org/10.1016/j.compstruct.2017.09.091

34. B. Najafloo, A.M. Rezadoust, M. Latifi, Effect of through-the-thickness areal density and yarn fineness on the mechanical performance of threedimensional carbon-phenolic composites. J. Reinf. Plast. Compos. 35, 14471459 (2016). https://doi.org/10.1177/0731684416653839

35. G. Pappas, S. Joncas, V. Michaud, J. Botsis, The influence of throughthickness reinforcement geometry and pattern on delamination of fiberreinforced composites: Part II - Modeling. Compos. Struct. 181, 379-390 (2017). https://doi.org/10.1016/j.compstruct.2017.08.096

36. I. Gnaba, X. Legrand, P. Wang, D. Soulat, Literature review of tufted reinforcement for composite structures. \{|OP\} Conf. Ser. Mater. Sci. Eng. 254, 42011 (2017). https://doi.org/10.1088/1757-899x/254/4/042011

37. E. Chehura, G. Dell'Anno, T. Huet, S. Staines, S.W. James, I.K. Partridge, R. P. Tatam, On-line monitoring of multi-component strain development in a tufting needle using optical fibre Bragg grating sensors. Smart 
Mater. Struct. 23, 75001 (2014). https://doi.org/10.1088/0964-1726/23/7/ 075001

38. M. Rashid, K. Chetehouna, A. Cablé, N. Gascoin, Analysing Flammability Characteristics of Green Biocomposites: An Overview. Fire. Technol (2020). https://doi.org/10.1007/s10694-020-01001-0

39. C. Hui, P. Wang, X. Legrand, Improvement of tufting mechanism during the advanced 3-dimensional tufted composites manufacturing: To the optimisation of tufting threads degradation. Compos. Struct. 220, 423-430 (2019). https://doi.org/10.1016/j.compstruct.2019.04.019

40. A. Martins, Z. Aboura, W. Harizi, A. Laksimi, K. Khellil, Analysis of the impact and compression after impact behavior of tufted laminated composites. Compos. Struct. 184, 352-361 (2018)

41. G. Epoxy, SR InfuGreen 810, 33 (2017) 1-9

42. C. Baley, P. Davies, Y. Grohens, G. Dolto, Application of Interlaminar Tests to Marine Composites. A Literature Review. Appl. Compos. Mater. 11, 99-126 (2004). https://doi.org/10.1023/B:ACMA.0000012902.93986.bf

43. M. Xie, D.F. Adams, A plasticity model for unidirectional composite materials and its applications in modeling composites testing. Compos. Sci. Technol. 54, 11-21 (1995). https://doi.org/10.1016/0266-3538(95)00035-6

44. Y. He, A. Makeev, B. Shonkwiler, Characterization of nonlinear shear properties for composite materials using digital image correlation and finite element analysis. Compos. Sci. Technol. 73, 64-71 (2012). https://doi.org/1 0.1016/j.compscitech.2012.09.010

45. R. Taubert, U. Mandel, M. Hartmann, Influence of nonlinear material behavior on the effect of inter-fiber cracks in composite laminates. J. Compos. Mater. 51, 3819-3833 (2017). https://doi.org/10.1177/002199831 7694372

46. A.D./ D2344M-16, Standard Test Method for Short-Beam Strength of Polymer Matrix Composite Materials and Their Laminates, ASTM Int. West Consh (2016) PA. doi:https://doi.org/10.1520/D2344

47. ASTM International, Standard test method for measuring the damage resistance of a fiber-reinforced polymer matrix composite to a drop-weight impact event (2015). https://doi.org/10.1520/D7136_D7136M-15

48. ASTM International, Standard test method for compressive properties of rigid plastics (2015). https://doi.org/10.1520/D0695-15

49. ASTM International, Standard test method for tensile properties of polymer matrix composite materials (2017). https://doi.org/10.1520/D3039_D303 $9 \mathrm{M}-17$

50. W.C. Cui, M.R. Wisnom, Contact finite element analysis of three- and fourpoint short-beam bending of unidirectional composites. Compos. Sci. Technol. 45, 323-334 (1992). https://doi.org/10.1016/0266-3538(92)90047-7

51. A.P. Mouritz, J. Gallagher, A.A. Goodwin, Flexural strength and interlaminar shear strength of stitched GRP laminates following repeated impacts. Compos. Sci. Technol. 57, 509-522 (1997)

52. X. Du, F. Xue, Z. Gu, in Proc. Int. Symp. Compos. Mater. Struct. Experimental study of the effect of stitching on strength of a composite laminate (Technomic Lancaster, Pennsylvania, 1986), pp. 912-918

53. M.T. Cholakara, B.Z. Jang, C.Z. Wang, in Proc. 34th Int. SAMPE Symp. Deformation and failure mechanisms in 3D composites (Society for the Advancement of Materials and Process Engineering Covina, Covina, 1989), pp. 8-11

54. S. Adanur, Y.P. Tsao, in 50 Years Prog. Mater. Sci. Technol. 26 Th Int. SAMPE Tech. Conf. Stitch bonded textile structural composites (1994), pp. 25-34

55. S. Adanur, C.W.A. Tam, in Proc 2nd Int Conf Comp Engng. On-machine stitching of 3-D laminates for composites (1995), pp. 21-24

56. A. Mayadas, C. Pastore, F.K. Ko, Tensile and shear properties of composites by various reinforcement concepts. Adv. Technol. Mater. Process. 1985(30), 1284-1293 (1985)

57. N. Alif, L.A. Carlsson, L. Boogh, The effect of weave pattern and crack propagation direction on mode I delamination resistance of woven glass and carbon composites. Compos. Part B Eng. 29, 603-611 (1998). https:// doi.org/10.1016/S1359-8368(98)00014-6

58. F. Greco, L. Leonetti, P. Lonetti, P. Nevone Blasi, Crack propagation analysis in composite materials by using moving mesh and multiscale techniques. Comput. Struct. 153, 201-216 (2015). https://doi.org/10.1016/j.compstruc.2 015.03.002

59. S. Yang, Évaluation de l'apport simultané des coutures sur la perméabilité des préformes cousues et sur les performances mécaniques des structures composites cousues, Université de Technologie de Compiègne (2015)

60. N. Harris, N. Schinske, R. Krueger, B. Swanson, Multiaxial stitched preform reinforcements. Compos. Polym. 5, 77-89 (1992)
61. L.K. Jain, Y.-W. Mai, Recent work on stitching of laminated compositestheoretical analysis and experiments (Proc. ICCM-11, Gold Coast, 1997)

62. H. Dexter, J. Funk, in 27th Struct. Struct. Dyn. Mater. Conf. Impact resistance and interlaminar fracture toughness of through-the-thickness reinforced graphite/epoxy (1986), p. 1020

63. M.B. Dow, D.L. Smith, Damage-tolerant composite materials produced by stitching carbon fibers (1989)

64. C. Caneva, S. Olivieri, C. Santulli, G. Bonifazi, Impact damage evaluation on advanced stitched composites by means of acoustic emission and image analysis. Compos. Struct. 25, 121-128 (1993). https://doi.org/10.1016/02638223(93)90158-M

65. G.L. Farley, B.T. Smith, J. Maiden, Compression response of thick layer composite laminates with through-the-thickness reinforcement. J. Reinf. Plast. Compos. 11, 787-810 (1992). https://doi.org/10.1177/073168449201100705

66. N.E. Vandermey, D.H. Morris, J.E. Masters, Damage development under compression-compression fatigue loading in a stitched uniwoven graphite/ epoxy composite material. Interim Report No. 86, United States, 1991. https://www.osti.gov/biblio/5203166

67. K.W. Furrow, A.C. Loos, R.J. Cano, Environmental effects on stitched RTM textile composites. J. Reinf. Plast. Compos. 15, 378-419 (1996). https://doi. org/10.1177/073168449601500403

68. J.R. Reeder, Stitching vs. a Toughened Matrix: Compression Strength Effects. J. Compos. Mater. 29, 2464-2487 (1995). https://doi.org/10.1177/002199839502901805

69. H. Thuis, E. Bron, The effect of stitching density and laminate lay-up on the mechanical properties of stitched carbon fabrics, Natl. Lucht-En Ruimtevaartlaboratorium. Rep. NLR CR L 96126, 1996 (1996)

70. L. Francesconi, F. Aymerich, Impact damage resistance of thin stitched carbon/epoxy laminates. J. Phys. Conf. Ser. 628, 8 (2015). https://doi.org/10.1 088/1742-6596/628/1/012099

71. K.K. Verma, G. Padmakara, K.M. Gaddikeri, S. Ramesh, S. Kumar, S. Bose, The key role of thread and needle selection towards 'through-thickness reinforcement' in tufted carbon fiber-epoxy laminates. Compos. Part B Eng. 174, 106970 (2019). https://doi.org/10.1016/j.compositesb.2019.106970

72. K.H. Leong, I. Herszberg, M.K. Bannister, An investigation of fracture mechanisms of carbon epoxy laminates subjected to impact and compression-after-impact loading. Int. J. Crashworthiness. 1, 285-294 (1996)

73. A. Yudhanto, N. Watanabe, Y. Iwahori, H. Hoshi, The effects of stitch orientation on the tensile and open hole tension properties of carbon/ epoxy plain weave laminates. Mater. Des. 35, 563-571 (2012). https://doi. org/10.1016/j.matdes.2011.09.013

74. M. Bodaghi, I. Gnaba, X. Legrand, D. Soulat, P. Wang, M. Deléglise, C.H. Park, Inplane permeability changes of plain weave glass fabric induced by tufting. Adv. Compos. Mater. (2020). https://doi.org/10.1080/09243046.2020.1840687

\section{Publisher's Note}

Springer Nature remains neutral with regard to jurisdictional claims in published maps and institutional affiliations.

\section{Submit your manuscript to a SpringerOpen ${ }^{\circ}$ journal and benefit from:}

- Convenient online submission

- Rigorous peer review

- Open access: articles freely available online

- High visibility within the field

- Retaining the copyright to your article

Submit your next manuscript at $\boldsymbol{\nabla}$ springeropen.com 